\title{
Genetic diversity of Glossina fuscipes fuscipes along the shores of Lake Victoria in Tanzania and Kenya: implications for management
}

Oliver Manangwa ${ }^{1 *} \mathbb{D}$, Gamba Nkwengulila², Johnson O. Ouma ${ }^{3,4}$, Furaha Mramba ${ }^{5}$ Imna Malele ${ }^{1}$, Kirsten Dion Mark Sistrom ${ }^{7}$, Farrah Khan ${ }^{8}$, Serap Aksoy ${ }^{9}$ and Adalgisa Caccone ${ }^{6}$

\begin{abstract}
Background: Tsetse flies (Diptera: Glossinidae) are sole vectors for trypanosomiasis, which affect human health and livestock productivity in Africa. Little is known about the genetic diversity of Glossina fuscipes fuscipes, which is an important species in Tanzania and Kenya. The main objective of the study was to provide baseline data to determine the genetic variability and divergence of G. f. fuscipes in the Lake Victoria basin of Tanzania and Kenya in order to guide future vector control efforts in the region.

Findings: Two hundred and seventy five G. f. fuscipes from 8 sites along the shores of Lake Victoria were screened for genetic polymorphisms at 19 microsatellite loci. Samples were collected from two sites in Kenya and six sites in Tanzania. Four of the Tanzanian sites were located in the Rorya district, on the eastern shores of Lake Victoria, while the other two sites were from Ukerewe and Bukoba districts from the southern and western Lake Victoria shores, respectively. Four genetically distinct allopatric clusters were revealed by microsatellite analysis, which sorted the sampling sites according to geography, with sites separated by as little as $\sim 65 \mathrm{~km}$ belonging to distinct genetic clusters, while samples located within $\sim 35 \mathrm{~km}$ from each other group in the same cluster.

Conclusion: Our results suggest that there is ongoing genetic admixture within sampling sites located $\sim 35 \mathrm{~km}$ from each other, while sites located $\sim 65 \mathrm{~km}$ apart are genetically isolated from each other. Similar patterns emerged from a parallel study on G. f. fuscipes analyzed from the Lake Victoria Uganda shores. From a control perspective these results suggest that for sites within the same genetic cluster, control efforts should be carried out in a coordinated fashion in order to avoid re-invasions. Future work should focus on better quantifying the extent and spatial patterns of the observed genetic discontinuities of the G. f. fuscipes populations along the Tanzanian shores. This will aid in their control by providing guidelines on the geographical extent of the area to be treated at the same time.
\end{abstract}

Keywords: Glossina fuscipes fuscipes, Tsetse flies, Trypanosomiasis, Microsatellite genetic diversity, Lake Victoria basin

\footnotetext{
* Correspondence: okijanga@yahoo.com

${ }^{1}$ Vector and Vector Borne Disease Institute, P. O. Box 1026, Tanga, Tanzania

Full list of author information is available at the end of the article
} 


\section{Background}

Tsetse flies (Diptera: Glossina) remain to be insects of economic and medical importance in sub-Saharan Africa. They transmit pathogenic trypanosomes that cause sleeping sickness to humans and nagana to livestock [1, 2]. The occurrence of the disease in humans and livestock has greatly limited the development of agriculture and human health in the region [3]. Estimates by FAO show, Africa loses over 3 million cattle and other domestic livestock due to trypanosomiasis every year [4]. The annual losses, in terms of reduced meat and milk production and in terms of the costs related to treatment and controlling the disease, have been estimated at US $\$ 1.2$ billion [5]. No vaccine has been developed for the disease to date both for humans and cattle due to the ability of trypanosome parasites to change their surface proteins by antigenic variation $[6,7]$. Drugs which are used to treat cattle have been used for long time; as a result drug resistance is increasing rapidly which in the long run will seriously affect the use of these drugs for animal trypanosomiasis control. Similarly, drugs which are used to treat humans are toxic, expensive and difficult to administer at village settings and also have bad side effects $[1,8]$. Therefore, tsetse control remains the most effective method of reducing trypanosome infections in animals and human in sub-Saharan countries [6-9].

Glossina fuscipes fuscipes is one of the most important tsetse species in the Palpalis group, subgenus Nermohina Robineau-Desvoidy [10]. In Tanzania the species is widely distributed along the shores of Lake Victoria supported by vegetation growing close to the water [11]. The species is found at the eastern margin in Uganda which extends further east along the shores of Lake Victoria in Western Kenya. The fly is also found in southern Sudan, Chad, the Central African Republic, the Democratic Republic of Congo (DRC) and Angola [12, 13]. Various methods have been employed in tsetse control in different areas in Africa, but the success of these methods varied. Some of these interventions used in the past included bush clearing (destroying vector habitat), elimination of wild animals (reservoir host of the parasites), insecticide ground spraying, live bait technology and the use of baited traps and targets. Despite the fact that tsetse fly densities were temporarily reduced, some of the methods used in the past are not used today because of environment reason and also they are against animal conservation $[2,5,6]$. Sterile Insect Technique (SIT) and Sequential Aerial Technique (SAT) have become promising methods which have been successful used to eradicate tsetse flies in some parts of Africa. SIT was successfully used to eradicate Glossina austeni in Unguja Island in Tanzania $[2,14]$ and SAT has been successfully applied in the Okavango Delta in northern Botswana in the eradication of Glossina morsitans centralis [5]. The success of these control interventions depend much on the biogeographical limits of the target tsetse species in such a way that maximum benefit is gained from the natural barriers to reinvasion of the previous controlled areas [5]. One factor that can improve the application of various control methods is knowledge on tsetse population genetics in addition to ecological information [9]. Studying the genetic differentiation between different populations of G. f. fuscipes will lead to novel insights into the relationships between genetically distinct populations, including geographical distribution, hybridization and migration patterns. This knowledge can then be used to inform ongoing or planned vector control programs across a target geographical region to identify the most suitable areas to target control to avoid re-infestation of cleared habitats. Studies on the population structure of G. f. fuscipes have been carried out in some parts of East Africa, particularly along Lake Victoria shores in Uganda [8, 15-18], and reported high genetic structuring of the species in the area. All authors confirmed the presence of two distinct lineages of $G$. f. fuscipes in Uganda using mtDNA and microsatellites markers except author 18. The isolation of northern and southern G. $f$. fuscipes populations which were thought to occur as a result of fragmentation during extreme drought in East Africa warrants these populations to be treated separately during eradication. Likewise, population study of another tsetse riverine species G. palpalis gambiensis in Senegal also indicated the species was sufficiently isolated and currently eradication is underway $[9,19]$. However, population structure of G. p. palpalis in Burkina Faso and G. p. gambiensis in Equatorial Guinea indicated high gene flow compared to other riverine tsetse species $[20,21]$. Similarly, population structure study on the same species in Cameroon indicated the species had heterozygote deficit suggesting suppression to be the best option to control the tsetse species in the area [7].

Little is known on the population structure and gene flow of G. f. fuscipes in the Lake Victoria basin in Kenya and Tanzania. The information will be useful in the planning of effective regional control of the tsetse species in the Lake Victoria basin (the Lake Victoria basin includes parts of Uganda, Tanzania and Kenya) under Pan African Tsetse and Trypanosomiasis Eradication Campaign (PATTEC) initiative [22]. Lake Victoria basin is one among important regions which have been identified for tsetse eradication by PATTEC. This report describes patterns of genetic differentiation among G. $f$. fuscipes sampled in Tanzania and Kenya and relates them to the recommendations for guiding future vector control efforts in the region.

\section{Methods}

Study sites and data collection

Glossina fuscipes fuscipes were sampled at 8 localities around Lake Victoria, with 2 sites in Kenya (KIS and MAN) 
and 6 sites in Tanzania. These sites include 4 locations on the border of Tanzania and Kenya in the Rorya district (MAS, TOB, RAS and KIR), one in the Bukoba district at the border between Uganda and Tanzania (BUK), and one approximately in between these two areas in the Ukerewe district (UKE; Fig. 1). The average distance among the four sampling sites in the Rorya district ranged from 2 to $10 \mathrm{~km}$, the two sampling sites from Kenya (KIS and MAN) are $35 \mathrm{~km}$ apart, $\sim 65 \mathrm{~km}$ from the Rorya district samples, and $\sim 200 \mathrm{~km}$ away from the other two Tanzanian samples from the southern and western shores of Lake Victoria (BUK and UKE), which are also similarly distant from each other $(187 \mathrm{~km})$. Overall, 275 individual tsetse flies were collected using biconical and pyramid traps and preserved in cryotubes containing 90\% ethanol. Flies from the Tanzanian sites were collected in 2011 while the ones from the two Kenyan sites were collected in 2009. All samples were collected during the dry season. All study sites experience a bimodal rainfall pattern, short rains fall between October and December and long rains from March to May. The average annual rainfall in the basin is estimated to be $1,015 \mathrm{~mm}$
[23]. The vegetation of the study sites was bushy vegetation and was the same in all study sites (Fig. 2).

\section{DNA extraction and PCR analysis}

DNA extraction from tsetse legs was conducted using a Qiagen Micro Amp extraction kit (Qiagen, Hilden, Germany) according to the manufacturer's instructions. PCR and genotyping were conducted for microsatellite markers at 19 previously identified loci that are distributed across the genome [8]. PCR conditions used were in accordance with previously described methods [15]. Microsatellite peaks were scored for each individual sample using GeneMarker software [24]. Table 1 reports the number of flies genetically analyzed for each sampling site.

\section{Genetic analyses}

The program Genepop 4.2 [25] was used to test for deviations from Hardy-Weinberg equilibrium, estimate allelic richness (AR), calculate expected and observed heterozygosities ( $\mathrm{He}$ and $\mathrm{Ho}$ ), and evaluate levels of

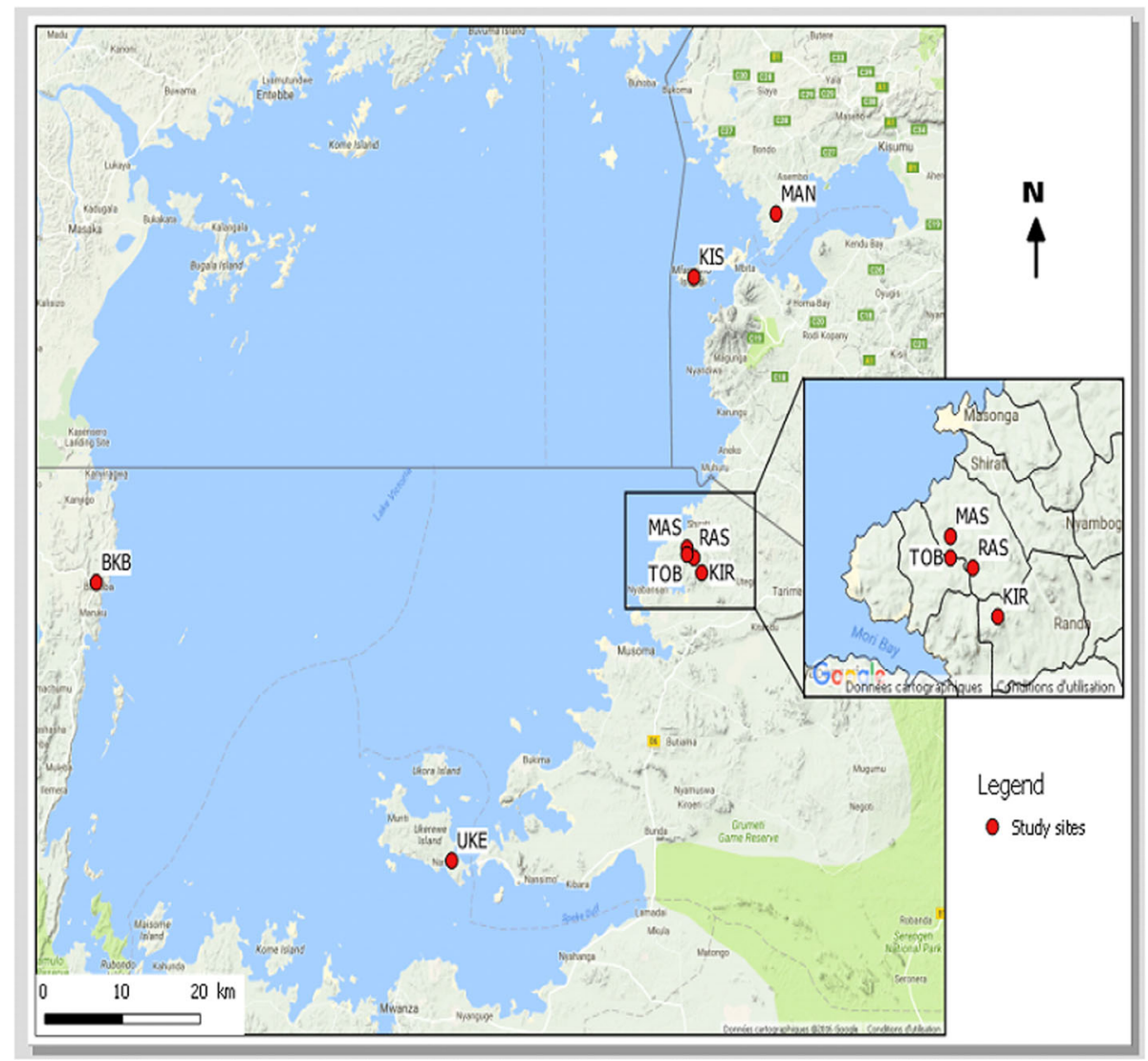

Fig. 1 Map showing sampling sites. Location of 8 sampling sites noted by red dots and a three letters code to identify sampling sites (BUK, Bukoba; MAN, Manga; KIR, Kirongwe; UKE, Ukerewe; KIS, Kisasi; RAS, Rasi Nyabero; TOB, River Tobwe; MAS, Masonga). The inset shows the location of the four sampling sites in the Rorya district. Lake Victoria is shown in light blue, as well as other major lakes in Uganda (Lake Kyoga and Lake Albert). Lines depict countries borders and the River Nile 


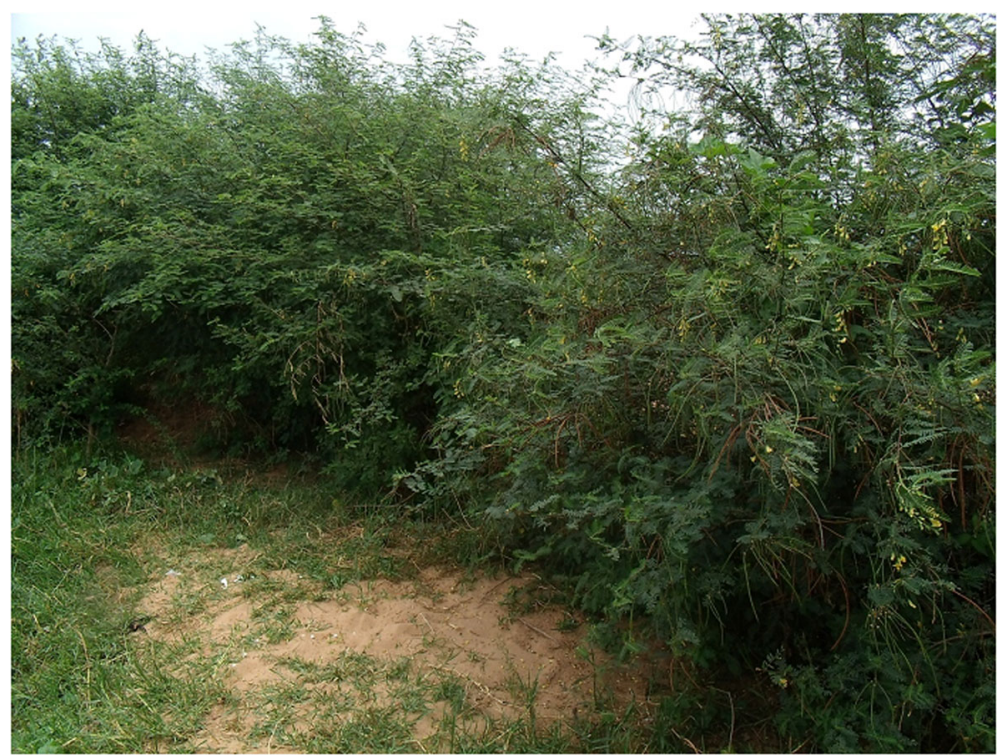

Fig. 2 Bushy vegetation in Rasi Nyabero village in Rorya district. A photo showing the vegetation along lake shores in Rorya District in Rasi Nyabero village where flies were trapped. All sites had the same vegetation

inbreeding (Fis). Pairwise $\mathrm{F}_{\mathrm{ST}}$ values between all sampling sites were calculated in Arlequin v 3.5 [26]. Significance was tested using 10,000 permutations. Genetic differentiation among tsetse sampling sites was analyzed using a model-based Bayesian clustering method implemented in Structure 2.3.3 [27]. The optimal number of clusters in the data was calculated using the ad hoc statistic $\triangle \mathrm{K}$ in STRUCUTURE HARVESTER [28]. The STRUCTURE analysis was run for $\mathrm{k}=1$ to 8 , with 10 replicates of each $\mathrm{k}$ value, for a million generations and a 'burn-in' period lasting the first 200,000 generations. Afterwards, the results from the STRUCTURE analysis were summarized across the 10 replicates using the Greedy method of the software CLUMPP [29], and distruct package was used to plot the results. We also used discriminant analysis of principal components
(DAPC) [30] conducted with the $\mathrm{R}$ adegenet package [31] to determine genetic structure. In addition, we used the Bayesian Information Criterion (BIC) to determine the most likely number of clusters in our data [32].

To investigate patterns of migration and identify any probable migrants within our dataset, we used GeneClass2 [33]. GeneClass2 computes the probability of an individual's observed multilocus genotype belonging to a given population. As such, the program can detect whether an individual is a resident of the sampled population or a first generation migrant. Effective population sizes $\left(\mathrm{N}_{\mathrm{e}}\right)$ for the clustered populations were estimated under the linkage disequilibrium model with random mating included in the program NeEstimator v2 [34]. All alleles were taken into account regardless of frequency. Jackknife on loci calculations was implemented to generate $95 \%$ confidence bounds.

Table 1 Summary information on sampling sites and summary statistics for each samplings site and the patterns of genetic variation at 19 microsatellite loci for G. f. fuscipes tsetse flies from eight sampling sites along the Kenyan and Tanzania shores of Lake Victoria

\begin{tabular}{llllllllllll}
\hline Population & Code & District & Country & Longitude & Latitude & $N$ & AR & $H_{E}$ & $H_{O}$ & $F_{I S}$ & Cluster \\
\hline Bukoba & BUK & Bukoba & Tanzania & 34.048944 & -1.085306 & 41 & 2.89 & 10.31 & 7.74 & 0.35 & 1 \\
Ukerewe & UKE & Ukerewe & Tanzania & 33.141111 & -2.059444 & 51 & 3.37 & 11.32 & 10.32 & 0.23 & 2 \\
Rasi Nyabero & RAS & Rorya & Tanzania & 31.828056 & -1.015 & 23 & 3.37 & 5.52 & 3.89 & 0.38 & 3 \\
Kirongwe & KIR & Rorya & Tanzania & 34.077778 & -1.0425 & 24 & 3 & 5.07 & 3.5 & 0.46 & 3 \\
Masonga & MAS & Rorya & Tanzania & 34.023056 & -1.112778 & 24 & 3.11 & 7.44 & 5.61 & 0.35 & 3 \\
River Tobwe & TOB & Rorya & Tanzania & 34.023056 & -1.094167 & 24 & 3.68 & 6.62 & 4.42 & 0.44 & 3 \\
Kisasi & KIS & Kisasi & Kenya & 33.96268 & -0.47637 & 48 & 4.53 & 19.85 & 20.53 & -0.02 & 4 \\
Manga & MAN & Manga & Kenya & 34.25125 & -0.35534 & 40 & 4.94 & 15.98 & 16.12 & 0.02 & 4 \\
\hline
\end{tabular}

Abbreviations: $N$, number of genetically tested samples, $A R$ mean allelic richness across all loci; $H_{O}$, observed heterozygosity, $H_{E}$ expected heterozygosity, $F_{I S}$ the inbreeding coefficient 


\section{Results and discussion}

In the present study, a total of 275 tsetse flies were genotyped at 19 microsatellite loci. According to inbreeding coefficient values for each population, no loci deviated significantly from Hardy-Weinberg equilibrium (Table 1, Additional file 1: Table S1). The number of alleles, a measure of genetic diversity, varied from 4.1 in Rasi Nyabero (RAS) to 5.6 in Manga (MAN). The number of alleles per locus varied from 2 in D101 to 15 in GmA06 with an average of 9.4. Mean allelic richness $\left(A_{R}\right)$ ranged from 2.89 to 4.94 across the sites. No significant differences were observed between observed and expected heterozygosities $\left(\mathrm{H}_{\mathrm{E}}\right.$ ranged from 5.07 to 19.85 per site, and $\mathrm{H}_{\mathrm{O}}$ ranged from 3.50 to 20.53 per site). These values are similar to the ones reported for G. f. fuscipes populations around Lake Victoria shores in Uganda $[6,19]$ and suggest that G. f. fuscipes flies in this region harbor a wealth of genetic diversity and thus have the long term potential to adapt to ecological changes in the area.

$\mathrm{F}_{\mathrm{ST}}$ values revealed significant genetic differentiation among sampling sites over $60-65 \mathrm{~km}$ apart, with notable exceptions being the significant $\mathrm{F}_{\mathrm{ST}}$ values found between two close sampling sites in the Rorya district (KIR and RAS, $<6 \mathrm{~km}$ apart, Additional file 1: Table S2) and the lack of significance for $\mathrm{F}_{\mathrm{ST}}$ values between samples from KIS and either RAS or MAN, located $\sim 68-71 \mathrm{~km}$ from
KIS (Additional file 1: Table S2). When the population structure was investigated using Bayesian clustering and multivariate analyses, the data was most consistent with 4 distinct population clusters (Fig. 3; Additional file 1: Figure S1, and Additional file 1: Figure S2), with $\mathrm{F}_{\mathrm{ST}}$ values between clusters being all statistically significant and ranging from 0.231 to 0.341 (Additional file 1: Tables S3 and S4). Clusters 1 and 2 group flies from BUK and UK in Bukoba and Ukerewe districts, respectively. Cluster 3 comprises flies from all the Rorya district sampling sites (Rasi Nyabero, RAS; Kirongwe, KIR; Masonga, MAS; and River Tobwe, TOB). Cluster 4 includes the two Kenyan locations (Kisasi, KIS and Manga, MAN). Individual flies collected in sampling sites within these clusters assign mostly to their respective clusters with only a few individuals showing signs of genetic admixture with another cluster. The high genetic differentiation $\left(\mathrm{F}_{\mathrm{ST}}=0.341 ; \mathrm{F}_{\mathrm{ST}}=0.308\right.$ and $\mathrm{F}_{\mathrm{ST}}=0.286$ ) recorded in this study is consistent with earlier reports on the same species in other areas of East Africa and is likely a consequence of genetic drift. In the riverine and lacustrine tsetse species, such as G. f. fuscipes, wet season dispersion from dry season refugia is thought to establish demes in which genetic drift leads to differentiation $[8,16,18]$. Similar results have been reported also for other riverine tsetse species

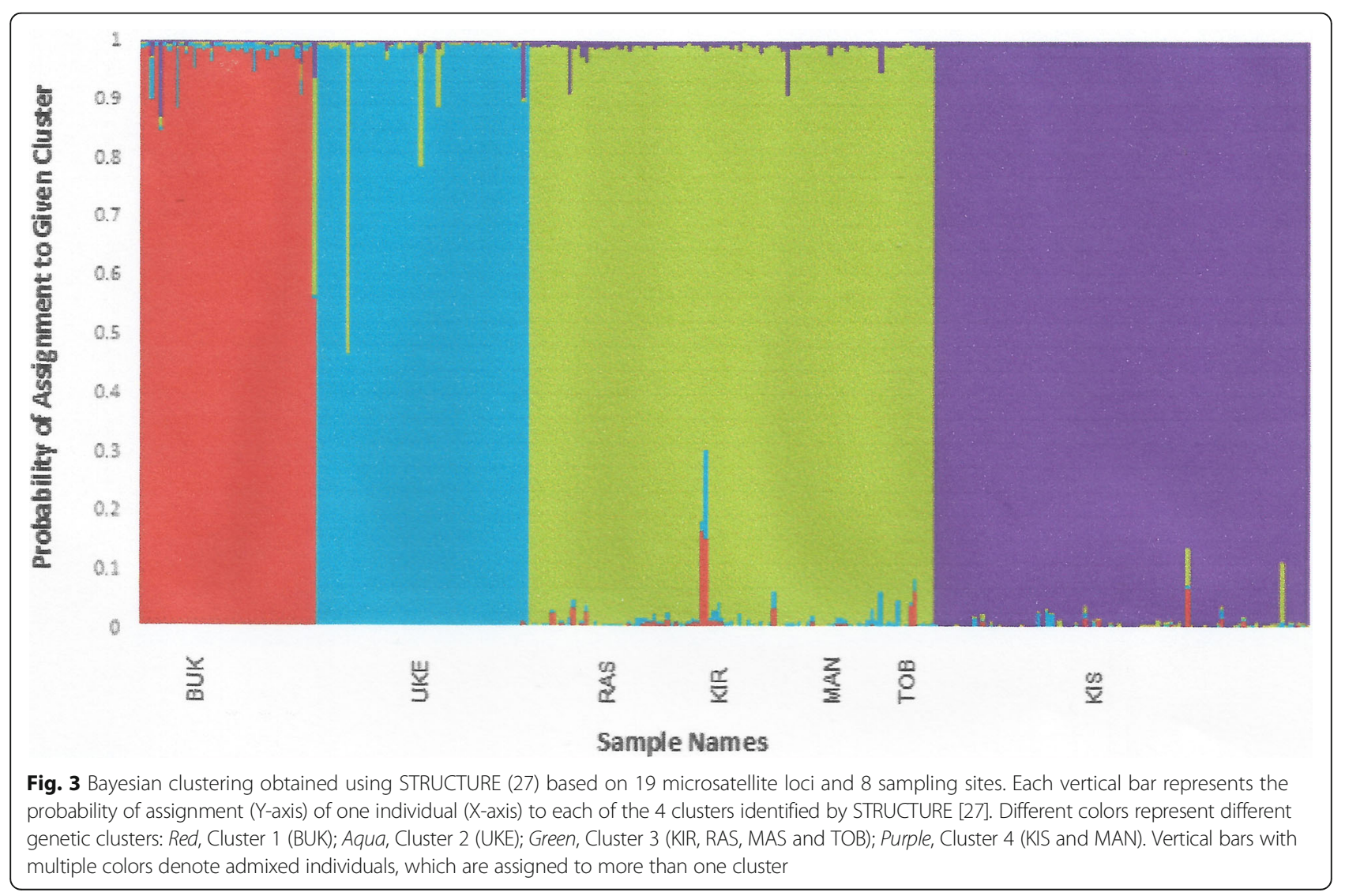


in West Africa which include G. tachinoides in Ghana $[35,36]$, G. p. gambiensis in Niayes-Senegal $[9,37]$ and G. p. palpalis in Cote d'Ivore [38]. However different results of similar species (G. p. palpalis) in Cameroon indicated the species formed a large panmixia population suggesting suppression to be the best option for the vector control [7]. In contrast to other riverine tsetse species, G. swynnertoni, a savannah species from northern Tanzania, have been reported to have the high level of gene flow [39]. Geographical distance and ecological differences are factors that are involved in these genetic differences of flies [40].

The presence of admixed genotypes within clusters 2 and 3 (Fig. 3) suggests ongoing or recent gene flow among sampling locales. This is confirmed by the GeneClass2 analysis aimed to detect first generation migrants, which identified nine likely migrants: three between clusters 1 and 3, two between clusters 2 and 3, and four between clusters 3 and 4 (Fig. 4). However, given the lack of data for intermediate locations, it is not possible to evaluate if this mixing is due to gene flow from intermediate locations or long-range dispersal. These patterns of genetic discontinuities mirror the ones obtained for the same species along the Uganda coast of Lake Victoria, where among similarly spaced samples genetic discontinuities were identified using microsatellite loci [16].

Although estimates of effective population size (Ne) were not uniform among sampling sites, and given the confidence intervals for clusters 3 and 4 (Fig. 4), the $\mathrm{Ne}$ estimates may not be very reliable. The high genetic diversity $\left(\mathrm{F}_{\mathrm{ST}}=0.341 ; \mathrm{F}_{\mathrm{ST}}=0.308\right.$ and $\left.\mathrm{F}_{\mathrm{ST}}=0.286\right)$ recovered at some sampling sites (Table 1) points to large resident populations. Recent reports indicated high and varied G. $f$. fuscipes densities in the sampling sites analyzed in this study [11]. These data indirectly seem to support the existence of local large pockets of tsetse flies at these sampling sites. Further screening of tsetse flies at these and neighboring sites, including temporal collections to capture seasonal variations in fly population sizes and densities, would shed additional light on local tsetse population dynamics, which is of critical relevance for monitoring and control.

\section{Conclusions}

From a control perspective these results suggest that, given the genetic homogeneity among sampling sites from the Rorya district, these sites should be controlled and monitored together to guard against reinvasion from neighboring untreated areas. A similar strategy should be adopted for the region including the two Kenyan sampling sites. However, given that the microsatellite data show that Kenya and the Rorya district samples are genetically distinct even though they are only $\sim 65-80 \mathrm{~km}$ apart, control and monitoring effort may not necessarily need to include large geographical areas. Future studies should include a more uniform geographical representation of tsetse infested areas than in the current study to quantify the extent and spatial pattern of the genetic discontinuities found in this study among sampling sites located at varying geographical distances.

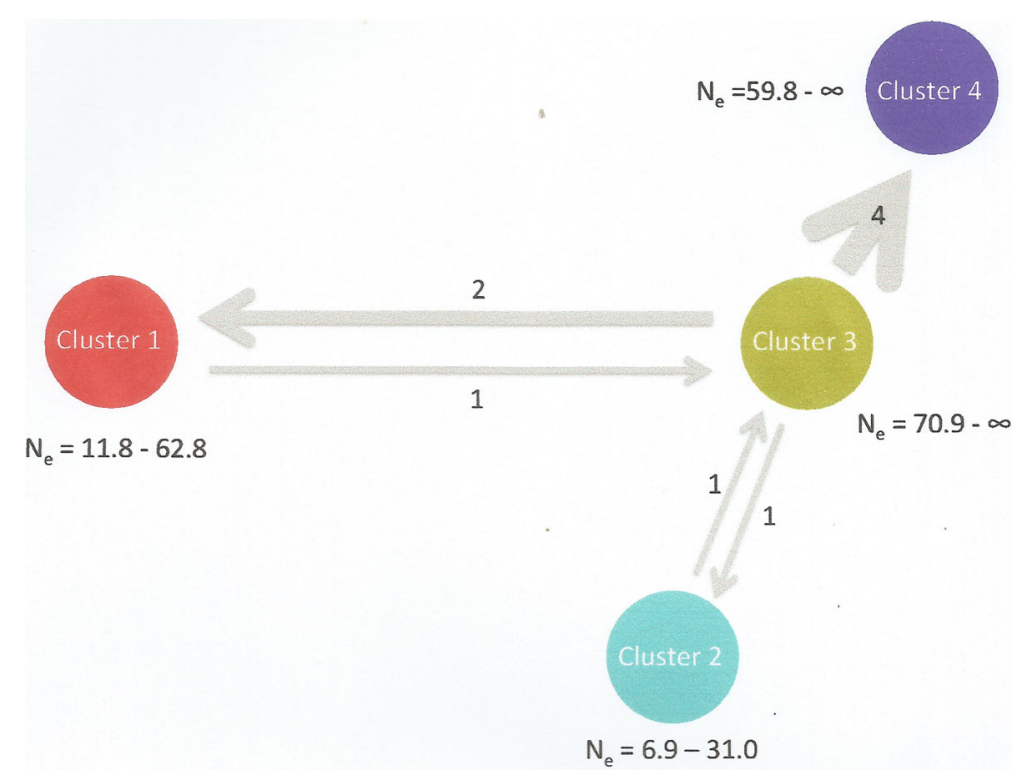

Fig. 4 Patterns of migration and effective population size ranges as determined in GeneClass2 and NeEstimator v2, respectively [33, 34]. The gray arrows indicate the direction of migration. Line weights are proportional to the number of migrants. The values adjacent to the arrows are the number of migrants identified within our data set. Distances between clusters are not proportional to actual distances between sample sites. Cluster 1: BUK; Cluster 2: UKE; Cluster 3: RAS, KIR, MAS and TOB; Cluster 4: KIS and MAN 


\section{Additional file}

Additional file 1: Table S1. Matrix of geographical distances among sampling sites ( $\mathrm{km}$ ). Table S2. Genetic differentiation between all population pairs. Values in bold are significant at the 0.05 level. Table S3. Genetic summary statistics for all 19 microsatellite loci. Summary statistics are shown for each of the 19 microsatellite loci: AR, allelic richness; $H_{0}$, observed heterozygosity; $H_{E}$, expected heterozygosity; $F_{I S}$, inbreeding coefficient and its $P$-value. Table S4. Genetic differentiation between the 4 clusters identified by STRUCTURE. Values in bold are significant at the 0.05 level. Key: Cluster $1=$ BUK, Cluster $2=$ UKE, Cluster $3=$ RAS, KIR, MAS, TOB, Cluster $4=\mathrm{KIS}, \mathrm{MAN}$. Figure S1. Delta K Log Likelihood plot for G. f. fuscipes clusters using the second order rate of change method [16]. The $\Delta \mathrm{K}$ plot for a given number of clusters $(K)$ shows that the most likely number of $G$. f. fuscipes clusters from the samples studied is four. Figure S2. Bayesian Information Criterion (BIC) versus the number of clusters ( $k$ ) generated for discriminant analysis of principal components (DAPC; Jombart et al., [30]) using Adegenet (Jombart, [31]) for all G. f. fuscipes microsatellite MLLs. A $k$ value of four was chosen to describe the data. Figure S3. Discriminant analysis of principal components (DAPC). Assignment of individuals from 8 sampling sites to each of the 4 identified clusters. Points represent individual genotypes sampled from a sampling site and are connected by lines to the 95\% confidence ellipse centroid of the respective population. Numbers refer to the clusters identified by the STRUCTURE analyses (Fig. 3) (DOC 328 kb)

\section{Abbreviations}

AR: Allelic richness; BIC: Bayesian Information Criterion; BUK: Bukoba; D101: Primer name derived from loci (D101) for assessing genetic diversity; DAPC: Discriminant Analysis of Principal components; F IS $_{\text {: Inbreeding }}$ coefficient; GmA06: Primer name derived from the loci of mutant lines of interest for assessing genetic diversity; He: Expected heterozygosity; Ho: Observed heterozygosity; KIR: Kirongwe; KIS: Kisimani; MAN: Manga; MAS: Masonga; Ne: Effective population size; RAS: Rasi Nyabero; UKE: Ukerewe

\section{Acknowledgement}

We are grateful for the logistical support which was given by Vector and Vector Borne Disease Institute which enabled the field work to be done smoothly. Assistance provided by technicians Benedect Kimbisa and Godfrey Mashenga of Vector and Vector Borne Disease Institute on data collection was highly appreciated.

\section{Funding}

This investigation received financial support from UNICEF/UNDP/World Bank WHO Special Programme for Research and Training in Tropical Diseases (TDR) grant no. A80132 and NIH grants D43TW007391 and Al068932. The funders had no role in study design, data collection and analysis, decision to publish, or preparation of the manuscript.

\section{Availability of data and materials}

All data generated or analysed during this study are included in this published article and its additional files.

\section{Authors' contributions}

OM, JOO, AC, IIM, GN and SA conceived the study; OM collected samples from the field, and OM and FK carried out the wet lab analyses. OM, MS and FK analyzed the data, OM, JOO, AC, GN and MS interpreted the data, JOO, GN, AC, IIM, FM and SA supervised the studies. JOO, IIM, AC, GC and SA obtained funding for the studies. OM and FK wrote the initial draft of the manuscript. All authors read and approved the final manuscript.

\section{Competing interests}

The authors declare that they have no competing interests.

\section{Consent for publication}

Not applicable.

Ethics approval and consent to participate Not applicable.

\section{Publisher's Note}

Springer Nature remains neutral with regard to jurisdictional claims in published maps and institutional affiliations.

\section{Author details}

${ }^{1}$ Vector and Vector Borne Disease Institute, P. O. Box 1026, Tanga, Tanzania. ${ }^{2}$ Department of Zoology, University of Dar es Salaam, P. O. Box 35064, Dar es Salaam, Tanzania. ${ }^{3}$ Africa Technical Research Centre, Vector Health International, P.O. Box 15500, Arusha, Tanzania. ${ }^{4}$ Biotechnology Research Institute, Kenya Agricultural and Livestock Research Organization, P.O. Box 362-00902, Kikuyu, Kenya. ${ }^{5}$ Tanzania Veterinary Laboratory Agency (TVLA), P. O. Box 9154, Dar es Salaam, Tanzania. ${ }^{6}$ Department of Ecology and Evolutionary Biology, Yale University, New Haven, Connecticut, USA. ${ }^{7}$ School of Natural Sciences, University of California, Merced, CA, USA. ${ }^{8}$ Department of Molecular, Cellular, and Developmental Biology, Yale University, New Haven, CT, USA. ${ }^{9}$ Yale School of Public Health, Yale University, 60 College Street, New Haven, CT, USA.

Received: 6 September 2016 Accepted: 16 May 2017

Published online: 30 May 2017

\section{References}

1. Echodu R, Sistrom M, Hyseni C, Enyaru J, Okedi L, Aksoy S, Caccone A. Genetically distinct Glossina fuscipes fuscipes populations in the Lake Kyoga Region of Uganda and its relevance for human African trypanosomiasis. Bio Med Res Int. 2013:614721:2-4.

2. Leak SGA. Tsetse biology and ecology. Wallingford: CABI Publishing; 1999. p. 189-90.

3. Msangi AR, Kiwia NE, Mramba F, Malele II, Kitwika WA, Byamungu MB, et al. After Zanzibar using SIT Mafia is next. Proceedings ISCTRC. Mombasa 1999;30.

4. FAO. Impacts of trypanosomiasis on African agriculture. PAAT Technic Sci Series. 2000;2:4-8.

5. Kuzoe FAS, Schofield CJ. Strategic review of traps and targets for tsetse and African trypanosomiasis control. UNICEF/UNDP/World bank /WHO Special Programme for Research and Training in Tropical Diseases (TDR). 2004;9-15.

6. Aksoy S. Control of tsetse flies and trypanosomes using molecular genetics. J Vet Parasitol. 2003:115:125-45.

7. Mélachio TTT, Njiokou F, Ravel S, Simo G, Solano P, Meeûs T. Effect of sampling methods, effective population size and migration rate estimation in Glossina palpalis palpalis from Cameroon. Infect Genet Evol. 2015;33:150-7.

8. Beadell JS, Hyseni C, Abilla PP, Azabo R, Enyaru JCK, Ouma JO, et al. Phylogeography and population structure of Glossina fuscipes fuscipes in Uganda: Implications for control of tsetse. PLoS Negl Trop Dis. 2010;4:636.

9. Solano P, Delarocque S, Cuisance D, Geoffroy B, Demeeus T, Cuny G, Duvallet G. Intraspecific variability in natural populations of Glossina palpalis gambiensis and morphometric analyses. Med Vet Entomol. 2010;13:401-7.

10. Gooding RH, Krasfur ES. Tsetse genetics. Contributions to biology, systematics, and control of tsetse flies. Annu Rev Entomol. 2005:50:101123.

11. Manangwa O, Ouma JO, Msangi A, Mramba F, Gamba N. Distribution and population size of G. f. fuscipes (tsetse flies) along the Lake Victoria, for trypanosomiasis management in Tanzania. Livestock Res Rural Dev. 2015;27:1-2.

12. Albert M, Wardrop NA, Atkinson PM, Torr SJ, Welburn SC. Tsetse fly (G. f. fuscipes). distribution in the Lake Victoria Basin of Uganda. PLoS Negl Trop Diseases. 2015;9(4):2-3

13. Rogers DJ, Robinson TP. Tsetse distribution. In: Maudin I, Holmes PH, Miles MA, editors. The Trypanosomes. Wallinford: CABI publishing; 2004. p. 139-79.

14. Vreysen MJB, Saleh KM, Ali MY, Abdulla AM, Zhu ZR, Juma KG, et al. Glossina austeni (Diptera: Glossinidae) eradicated on the island of Unguja, Zanzibar, using the sterile insect technique. J Appl Entomol. 2000:93:123-35.

15. Echodu R, Beadell JS, Okedi LM, Hyseni C, Aksoy S, Caccone A. Temporal stability of Glossina fuscipes fuscipes populations in Uganda. Parasit Vectors. 2011:4:2-3.

16. Hyseni C, Kato AB, Okedi LM, Masembe C, Ouma JO, Aksoy S, et al. The population structure of Glossina fuscipes fuscipes in the Lake Victoria basin in Uganda: implications for vector control. Parasit Vectors. 2012;5:222.

17. Kato BA, Hyseni C, Okedi LM, Ouma JO, Aksoy S, Caccone A, Masembe C. Mitochondrial DNA sequence divergence and diversity of Glossina fuscipes fuscipes in the Lake Victoria basin of Uganda: implications for control. Parasit Vectors. 2015;8:385.

18. Krafsur ES, Marquez JG, Ouma JO Structure of some East African Glossina fuscipes fuscipes populations. Med Vet Entomol. 2008;22:222-7. 
19. Kagbadouno M, Camara M, Bouyer J, et al. Tsetse elimination: its interest and feasibility in the historical sleeping sickness focus of loos islands, Guinea. Parasite. 2009;16(1):29-35.

20. Bouyer J, Sibert A, Desquesnes M, Cuisance D, De La Rocque S. A diffusion model for Glossina palpalis gambiensis in Burkina Faso. In: Vreysen MJB, Robinson AS, Hendrichs J, editors. Area-wide control of insect pests. From research to field implementation. Dordrecht: Springer; 2007. p. 221-8.

21. Dyer NA, Furtado A, Cano J, et al. Evidence for a discrete evolutionary lineage within Equatorial Guinea suggests that the tsetse fly Glossina palpalis palpalis exists as a species complex. Mol Ecol. 2009;18(15):3268-82.

22. Schofield CJ, Kabayo JP. Trypanosomiasis vector control in Africa and Latin America. Parasit Vectors. 2008;1(24):1756-3305

23. Makalle AMP, Obando J, Bamutaze Y. Effects of land use practices on livelihoods in the transboundary sub-catchments of the Lake Victoria Basin. Afr J Environ Sci Technol. 2008;2(10):309.

24. Soft genetics. GeneMarker genotyping software. Release 1.85. Soft Genetics LLC, State College 2009.

25. Rousset F. GENEPOP'007 a complete re-implementation of the Genepop software for Windows and Linux. Mol Ecol Resour. 2008;8:103-6.

26. Excoffier $L$, Lischer HEL. Arlequin suite ver 3.5. A new series of programs to perform population genetics analyses under Linux and Windows. Mol Ecol Resour. 2010;10:564-7.

27. Pritchard JK, Stephens M, Donnelly P. Inference of population structure using multilocus genoptype data. J Genet. 2000;155:945-59.

28. Earl DA, von Holdt BM. STRUCTURE HARVESTER. A website and program for visualizing STRUCTURE output and implementing the Evanno method. Conserv Genet Resour. 2012;4(2):359-61.

29. Jakobsson M, Rosenberg NA. CLUMPP: a cluster matching and permutation program for dealing with label switching and multimodality in analysis of population structure. Bioinformatics. 2007;23:1801-6.

30. Jombart T, Devillard S, Balloux F. Discriminant analysis of principal components: a new method for the analysis of genetically structured populations. BMC Genet. 2010;11:94

31. Jombart T. adegenet: a R package for the multivariate analysis of genetic markers. Bioinformatics. 2008;24(11):1403-5.

32. Evanno G, Regnaut S, Goudet J. Detecting the number of clusters of individuals using the software STRUCTURE: a simulation study. Mol Ecol. 2005; 14:2611-20

33. Piry S, Alapetite A, Cornuet JM, Paetkau D, Baudouin L, Estoup A. GeneClass2: A software for genetic assignment and first-generation migrant detection. J Hered. 2004;95:536-9.

34. Do C, Waples RS, Peel D, Macbeth GM, Tillett BJ, Ovenden JR. NeEstimator $\mathrm{V} 2$ : re-implementation of software for the estimation of contemporary effective population size $\left(N_{e}\right)$ from genetic data. Mol Ecol Resour. 2014;14: 209-14

35. Ravel S, Rayaisse JB, Courtin F, Solano P, De Meeûs T. Genetic signature of a recent southern range shift in Glossina tachinoides in East Burkina Faso. Infect Genet Evol. 2013:18:309-14.

36. Kone N, Bouyer J, Ravel S, Vreysen MJB, Domagni KT, Causse S, et al. Contrasting population structures of two vectors of African trypanosomoses in Burkina Faso: consequences for control. PLoS Negl Trop Dis. 2011;5:1217-20.

37. Bouyer J, Ravel S, Guerrini L, Dujardin JP, Sidibé I, Vreysen MJB, et al. Population structure of Glossina palpalis gambiensis (Diptera: Glossinidae) between river basins in Burkina-Faso: consequences for area-wide integrated pest management. Infect Genet Evol. 2010;10:326-9.

38. Ravel S, De Meeûs T, Dujardin JP, Zeze DG, Gooding RH, Dusfour I, et al. The tsetse fly Glossina palpalis palpalis is composed of several genetically differentiated small populations in the sleeping sickness focus of Bonon, Côte d'Ivoire. Infect Genet Evol. 2007:7:116-25.

39. Marquez JG, Malele II, Ouma JO, Krafsur ES. Glossina swynnertoni (Diptera: Glossinidae). effective population size and breeding structure estimated by mitochondrial diversity. Bull Entomol Res. 2006;96(4):353-60.

40. Solano P, de La Rocque S, Cuisance D, Geoffroy B, de Meeus T, et al. Intraspecific variability in natural populations of Glossina palpalis gambiensis from West Africa, revealed by genetic and morphometric analyses. Med Vet Entomol. 1999:13:401-7.

\section{Submit your next manuscript to BioMed Central and we will help you at every step:}

- We accept pre-submission inquiries

- Our selector tool helps you to find the most relevant journal

- We provide round the clock customer support

- Convenient online submission

- Thorough peer review

- Inclusion in PubMed and all major indexing services

- Maximum visibility for your research

Submit your manuscript at www.biomedcentral.com/submit

) Biomed Central 